\title{
The global cancer epidemic: opportunities for Canada in low- and middle-income countries
}

\author{
Ophira M. Ginsburg MD MSc, Timothy P. Hanna MD MSc, Theodore Vandenberg BA MD, \\ Anil A. Joy BSc MD, Mark Clemons MB MD, Melaku Game MD PhD, Ronald MacCormick MD, \\ Lorraine M. Elit MD MSc, Barry Rosen BSc MD, Yasmin Rahim BSc MD, William Geddie MD, \\ Simon B. Sutcliffe BSC MD, Mary Gospodarowicz MD
}

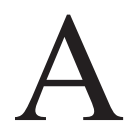
s economic disparities lessen in some areas of the world, the burden of cancer has increased. In 2008, cancer caused more deaths worldwide than tuberculosis, HIV/AIDS and malaria combined (8.1 million v. 4.3 million). ${ }^{1}$ More than $20 \%$ of all cancer deaths occur in low-income countries (per capita income of US $\$ 1005$ or less) $)^{2}$ and $50 \%$ occur in middle-income countries (per capita income of US\$1006-\$12 275). ${ }^{1,2}$ Case-fatality rates are $75 \%$ in low-income countries, compared with $46 \%$ in countries such as Canada. ${ }^{3}$ The greatest differences relate to cancers for which early detection and effective treatment influence outcome (Figure 1). 4.5 The burden of cancer is expected to worsen, with the greatest projected rise in the incidence of cancer in low- and lower to middle-income countries $(82 \%-70 \%){ }^{6}$

The context of this issue is important. Cancer is among the most important noncommunicable diseases that are increasingly prevalent in lowand middle-income countries (Figure 2). ${ }^{7}$ Over the next 20 years, the projected economic loss is $\$ 100$ billion in low-income countries and \$2.8 trillion in middle-income countries. ${ }^{8}$ The United Nations summit on noncommunicable diseases in September 2011 drew worldwide attention to this socioeconomic and development challenge. ${ }^{9}{ }^{10}$ Margaret Chan, director-general of the World Health Organization (WHO), called the meeting a "watershed event."

The growing burden of cancer in low- and middle-income countries reflects increasing life expectancy, population growth and the rise in risk factors. ${ }^{11,12}$ As tobacco consumption declined in high-income countries, this industry focused on markets in low- and middle-income countries. ${ }^{13,14}$ About $40 \%$ of the world's smokers now live in China and India. ${ }^{14}$ An estimated $18 \%$ of cancer deaths in low- and middle-income countries can be attributed to smoking..$^{15}$ Overall, about onethird of cancers in low- and middle-income countries are preventable, considering risk factors such as tobacco use, unhealthy diet, alcohol con- sumption, inactivity, pollution and infectious agents. ${ }^{15}$ For example, infections such as Helicobacter pylori, hepatitis $\mathrm{B}$ and $\mathrm{C}$, and human papillomavirus account for more than $26 \%$ of cancers in low- and middle-income countries. ${ }^{16,17}$

Faced with competing health priorities, most low- and middle-income countries lack the resources to address the challenge of cancer. Less than $5 \%$ of global health spending on cancer is in low- and middle-income countries, which have $80 \%$ of the global cancer burden. ${ }^{1,4}$ This inequity is compounded by stigma, poverty and a lack of political will, resulting in limited access to initiatives for cancer control. ${ }^{4}$ Even documentation is problematic. Only $21 \%$ of the world's population is included in cancer registries. ${ }^{18,19}$ Limited access to pathology expertise further compromises the quality of information.

Cancer prevention is compromised in a variety of ways, including inadequate implementation of the WHO Framework Convention on Tobacco Control..$^{20}$ In addition, concerns about the cost, public support and cultural acceptability have challenged the implementation of vaccination against human papillomavirus. ${ }^{21} \mathrm{~A}$ survey by the Union for International Cancer Control found a major lack of awareness about preventable causes of cancer, and over $25 \%$ of respondents from Africa and Asia did not think that cancer could generally be cured. ${ }^{22}$
Competing interests: None declared.

This article has been peer reviewed.

Correspondence to:

Timothy Hanna,

timothy.hanna@sswahs.nsw. gov.au

Ophira Ginsburg, ophira.ginsburg@wchospital .ca

CMAJ 2012. DOI:10.1503 /cmaj.111131

\section{KEY POINTS}

- Five percent of global health spending on cancer occurs in low- and middle-income countries, which have almost $80 \%$ of the worldwide burden of cancer.

- Cancer is a growing problem in low- and middle-income countries because of population growth, aging and unhealthy lifestyles, while infrastructure is incapable of providing adequate cancer care and control.

- Interventions and innovative solutions are urgently needed to reduce the growing burden of cancer.

- Canada's top priorities should include developing a global cancer network, assisting in planning and capacity building, research, and resource commitment. 
With a limited capacity for early detection, typically over $70 \%$ of patients with cancer present with advanced disease. ${ }^{5}$ For the vast numbers of patients who are uninsured or inadequately insured, ${ }^{23}$ the cost of cancer treatment is catastrophic. Given these factors, the consequences of cancer are far greater in low- and middle-income countries. A diagnosis of cancer contributes to the vicious cycle of poverty.

Resources dedicated to cancer therapy are also lacking in low- and middle-income countries. There is a massive undersupply of radiotherapy. ${ }^{24}$ In 12 Asia-Pacific countries, there are only one-third of the number of machines needed ${ }^{25,26}$ Despite the fact that most essential drugs are off-patent and 22 are on the WHO Essential Medicines List, the availability of chemotherapy is limited. ${ }^{6,27}$ Overall, the lack of qualified professionals limits surgical capacity ${ }^{28}$ and there are limited training resources for cancer. Migration of health care workers adds to this problem. According to the Center for Global Development, at least $40 \%$ of African-born physicians work outside their country of origin. ${ }^{29}$

Palliative care is often left to families because of stigma, lack of training and poor access to narcotics. ${ }^{27,30}$ There is an 1800-fold difference between the richest $10 \%$ and poorest $10 \%$ of countries in the use of opioids for pain among patients with cancer or HIV/AIDS. ${ }^{27}$

\section{Justification for action}

The goal of the Union for International Cancer Control is to eliminate cancer as a life-threatening disease for future generations. Its members include professional organizations and cancer centres, cancer control and advocacy organizations, and patient support groups. ${ }^{31}$ In 2006, the Union for International Cancer Control's World Cancer Declaration called for urgent measures to control the increasing burden of cancer worldwide (Box 1). ${ }^{32}$ The call for members and the public to sign the declaration resulted in over 511000 signatures, which were submitted to the United Nations' summit on noncommunicable diseases.

In 2011, the Global Task Force on Expanded Access to Cancer Care and Control published Closing the Cancer Divide, ${ }^{27}$ which highlights the challenges and explores specific opportunities to affect the global burden of cancer. In all, 115 authors from 56 countries, including Canada, challenged cancer-related myths, including the myth that the efforts to narrow the cancer divide are unnecessary, unaffordable, unattainable and inappropriate. Similar arguments were heard a decade ago as justifications for inaction against HIV/AIDS.

The report suggests that, given the projected economic losses due to cancer, we cannot afford not to address these inequities. In addition, investment in cancer control will mitigate the burden of

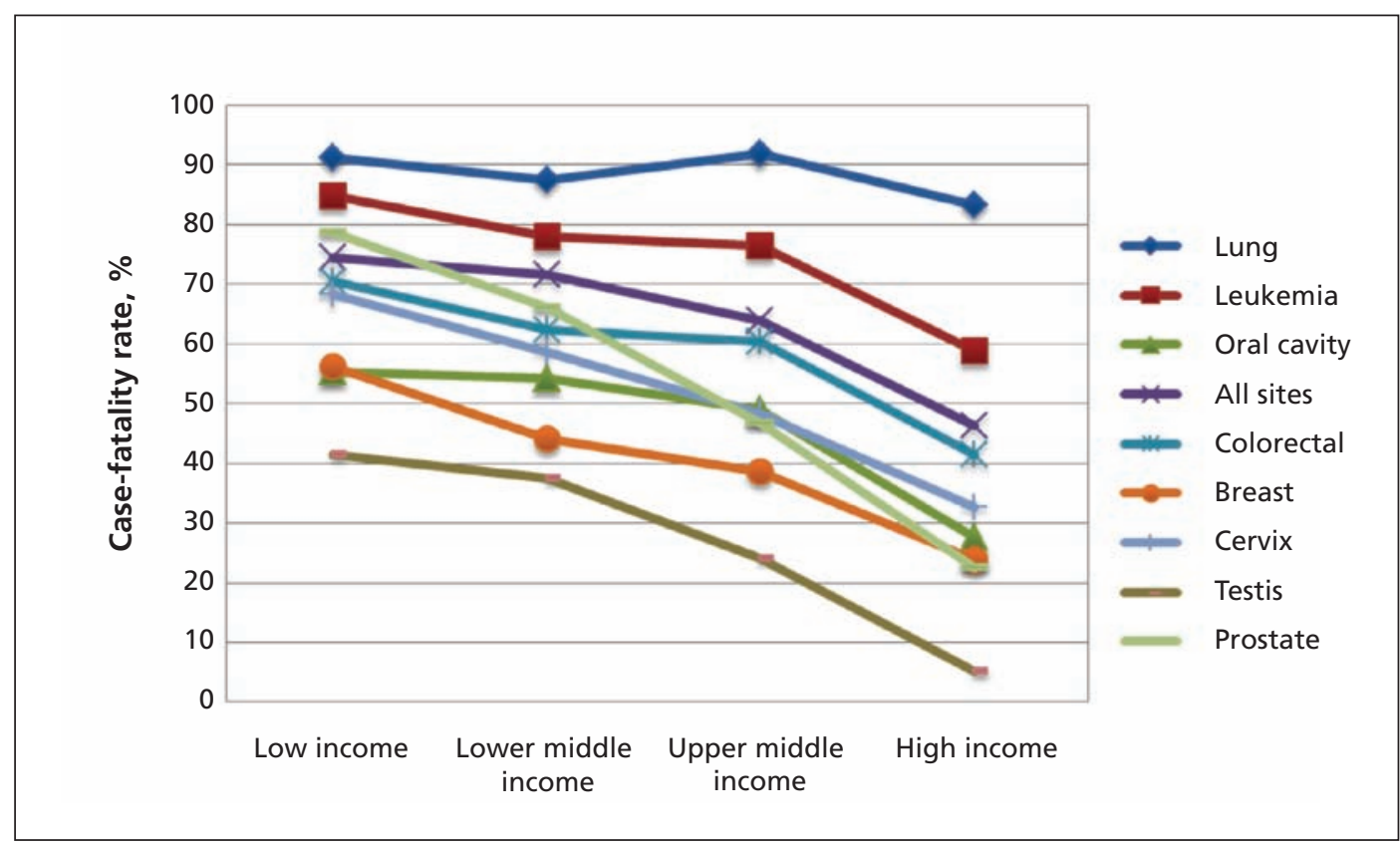

Figure 1: Cancer case-fatality rates by country income and site. ${ }^{3}$ The case-fatality rate is the ratio of cancer mortality over the incidence. When incidence and mortality are stable over time, the case-fatality rate represents the risk of dying of cancer among those who have cancer. Country income is from the World Bank, July 2009. Cancer incidence and mortality data (2002) are from the International Agency for Research on Cancer. Female case-fatality rates are calculated for breast and cervical cancer and male case-fatality rates for testicular and prostate cancer. "All sites" refers to all cancers, not just those sites described in this figure. 
a wide range of diseases. ${ }^{6,27}$ Initiatives to improve pain control for cancer would also help people with other conditions. ${ }^{27,33}$ Costs can be dramatically lowered with innovative financing and procurement, similar to what the GAVI Alliance has achieved for vaccines. ${ }^{27,34}$ Closing the Cancer Divide suggests numerous ways to build on the available resources. ${ }^{27}$ For example, cancer screening for breast and cervical cancer can be partnered with maternal and child health, sexual and reproductive health programs, and telemedicine will help all health and education programs. ${ }^{27,35}$

Cancer is a major public health problem in low- and middle-income countries and will continue to grow unless there is substantial international action.

\section{Opportunities for Canadians in global cancer control}

Canada is not effectively engaged in global cancer control, although we have opportunities to support global action. As a high-resource country with the capacity to assist, we have a moral obligation to provide leadership and action. We have the expertise. Members of the Union for
International Cancer Control, which include the Canadian Partnership Against Cancer, Canadian Cancer Society, Canadian Institutes of Health Research, BC Cancer Agency, Cancer Care Nova Scotia, Cancer Care Ontario, Canadian Association of Radiation Oncology, Princess Margaret Hospital, the Department of Oncology at McGill University and the Colorectal Cancer Association of Canada, ${ }^{31}$ have all helped improve cancer outcomes in Canada. The question is how these and other cancer organizations can support global cancer control. We propose the following avenues for engagement.

\section{Support cancer control}

We recommend that Canadian stakeholders sign the World Cancer Declaration ${ }^{32}$ and attend the Union for International Cancer Control's World Cancer Congress in Montréal Aug. 27-30, 2012. We also encourage Canada's institutions to join and become involved in the Union for International Cancer Control.

\section{Form a Canadian global cancer network}

A number of Canadians are involved in global cancer control efforts, including the authors of this paper. ${ }^{36-39}$ Among the initiatives are a

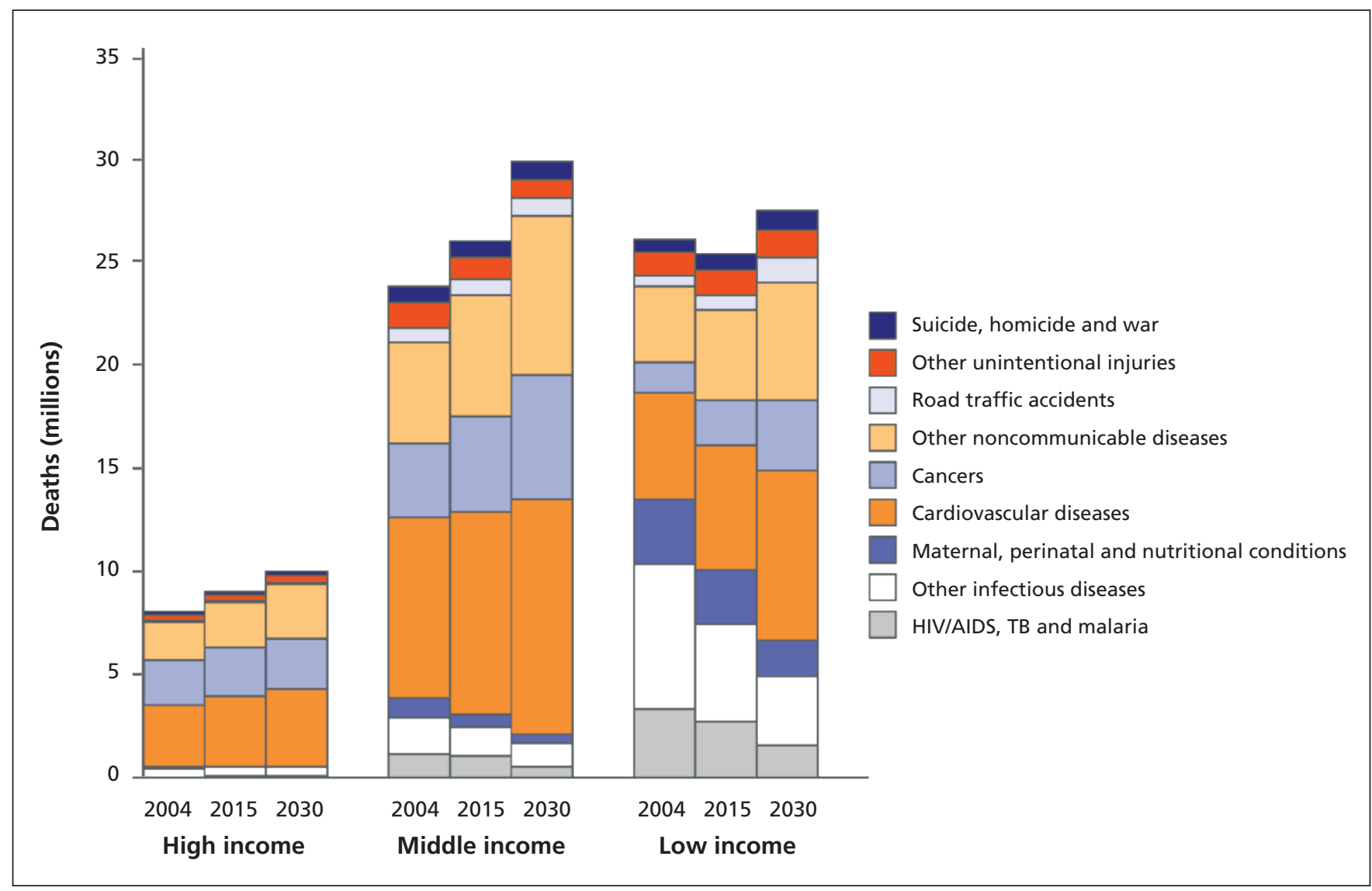

Figure 2: Projected deaths by cause and country income: 2004, 2015, 2030. "Other non-communicable diseases" include diabetes, chronic respiratory disease and mental illness. Reproduced with permission, from the World Health Organization. 
national oncology program in Yemen, ${ }^{37}$ cervical cancer programs in Kenya and Mongolia, ${ }^{38}$ cancer planning for East Africa and a breast centre in rural Bangladesh. ${ }^{39}$ The Canadian branch of the International Network for Cancer Treatment and Research is engaged in cancer control in Brazil and palliative care in India, Nepal, Brazil and Tanzania. The Canadian Association of Radiation Oncologists has an International communications working group. ${ }^{40}$

These efforts are largely being made by individual Canadians, and there is no coordinated approach to engage Canadians in global cancer control. A Canadian network within an existing Canadian entity would provide needed leadership, coordination of resources and strategy. Because there is currently no mechanism for documenting and sharing these experiences, we propose developing a registry of Canadian global cancer projects. This could be done through the Canadian Partnership Against Cancer or the Consortium of Universities for Global Health. The upcoming World Cancer Congress will provide an excellent venue to advance this initiative.

Share Canada's know-how in cancer control A recent survey by the WHO indicated that more than $40 \%$ of participating nations did not have an operational cancer plan. ${ }^{6}$ An international study assessing outcomes for lung, colorectal, breast

\section{Box 1: Union for International Cancer Control World Cancer} Declaration - targets by $2020^{31}$

- Sustainable delivery systems will be in place to ensure that effective programs for cancer control are available in all countries.

- The measurement of the global burden of cancer and the impact of interventions for cancer control will have improved significantly.

- Global consumption of tobacco, obesity and intake of alcohol will be significantly lower.

- Populations in areas affected by human papillomavirus and hepatitis B virus will be covered by universal vaccination programs.

- Public attitudes toward cancer will improve, and damaging myths and misconceptions will be dispelled.

- Many more cancers will be diagnosed when still localized through screening and early detection programs and high levels of public and professional awareness about important warning signs of cancer.

- Access to accurate cancer diagnosis, appropriate treatment, supportive care, rehabilitation services and palliative care will have improved for all patients worldwide.

- Effective measures for pain control will be available universally to all cancer patients in pain.

- The number of training opportunities available for health professionals in different aspects of cancer control will have improved significantly.

- Emigration of health workers with specialist training in cancer control will be dramatically reduced.

- There will be major improvements in the rates of cancer survival in all countries. and ovarian cancer in eight developed nations found Canada ranked consistently in the top three. ${ }^{41}$ Sharing Canadian experiences in design, implementation and evaluation of cancer control could accelerate progress in cancer control in low- and middle-income countries.

\section{Engage in cancer control research in low- and middle-income countries}

The research priorities for cancer identified in WHO's noncommunicable disease research agenda include tracking the cancer burden and risk factors, developing methods to apply cancer prevention strategies, developing means to train health professionals, studying the cost-effectiveness of specific approaches, and identifying ways to reduce barriers to access for diagnosis, treatment, palliation and rehabilitation. ${ }^{42}$ Canadian institutions should support research efforts relevant to global cancer control. Cancer control could be enhanced by low-cost technologies for diagnosis and treatment. The potential market for these technologies in low- and middle-income countries is an important opportunity for Canadian research and development. In addition, sustaining systems in highresource countries may require more cost-effective solutions emanating from low- and middle-income countries (e.g., interdisciplinary practice, alternate models of care and task shifting).

\section{Commit resources}

To our knowledge, this is the first formal attempt to consider Canada's role in the global fight against cancer. We want to begin a dialogue among cancer control stakeholders and consider direct engagement or indirect support of efforts such as those outlined here. To make a substantive impact on global cancer control, we appeal to Canadian cancer organizations to dedicate a small proportion of resources (e.g., $0.5 \%-1 \%$ ) toward meeting these recommendations.

\section{Conclusion}

There is much hope for progress in tackling the great burden of cancer in low- and middleincome countries. Canada is well positioned to make major contributions and has a moral obligation to provide leadership and action. We have much to learn together with low- and middleincome countries, particularly about sustainable models for health care delivery. Individual actions, development of a Canadian global cancer network, planning and capacity building, research, and resource commitment are top priorities. Action on the recommendations listed here would enable Canada to effectively contribute to global cancer control. 


\section{References}

1. World Health Organization. Projections of mortality and burden of disease, 2004-2030. Geneva (Switzerland): The Organization; 2008. Available: www.who.int/healthinfo/global burden _disease/projections/en/index.html (accessed 2011 Aug. 13).

2. The World Bank. How we classify countries. Washington (DC): The Bank; 2010. Available: http://data.worldbank.org/about /country-classifications (accessed 2011 Aug. 13)

3. Breakaway: the global burden of cancer - challenges and opportunities: a report from the Economist Intelligence Unit. London (UK): The Economist Intelligence Unit; 2009.

4. Farmer P, Frenk J, Knaul FM, et al. Expansion of cancer care and control in countries of low and middle income: a call to action. Lancet 2010;376:1186-93.

5. Sankaranarayanan R, Swaminathan R, Brenner H, et al. Cancer survival in Africa, Asia, and Central America: a populationbased study. Lancet Oncol 2010;11:165-73.

6. Alwan A, editor. Global status report on noncommunicable diseases 2010. Geneva (Switzerland): World Health Organization; 2011.

7. World Health Organization. The global burden of disease: 2004 update. Switzerland (Geneva): The Organization; 2008. Available: www.who.int/healthinfo/global_burden_disease/GBD _report_2004update_part2.pdf (accessed 2011 Jan. 24)

8. Bloom DE, Cafiero ET, Jané-Llopis E, et al. The global economic burden of non-communicable diseases. Geneva (Switzerland): World Economic Forum; 2011

9. United Nations General Assembly 66th Session. Political declaration of the High-Level Meeting of the General Assembly on the Prevention and Control of Non-communicable Diseases. New York (NY): United Nations; 2011.

10. United Nations General Assembly. Non-communicable diseases deemed development challenge of "epidemic proportions" in political declaration adopted during landmark General Assembly summit. New York (NY): United Nations; 2011. Available: www.un.org/News/Press/docs//2011/ga11138.doc.htm (accessed 2011 Nov. 15)

11. United Nations Department of Economic and Social Affairs World population prospects: the 2010 revision. New York (NY): United Nations; 2011. Available: http://esa.un.org/unpd/wpp /index.htm (accessed 2011 Aug. 6).

12. Mathers CD, Loncar D. Projections of global mortality and burden of disease from 2002 to 2030. PLoS Med 2006;3:e442.

13. Barry $\mathrm{M}$. The influence of the US tobacco industry on the health, economy, and environment of developing countries. $N$ Engl J Med. 1991;324:917-20.

14. World Health Organization. WHO report on the global tobacco epidemic, 2008 - MPOWER package. Geneva (Switzerland): The Organization; 2008.

15. Danaei G, Vander Hoorn S, Lopez AD, et al. Causes of cancer in the world: Comparative risk assessment of nine behavioural and environmental risk factors. Lancet 2005;366:1784-93.

16. Parkin DM. The global health burden of infection-associated cancers in the year 2002. Int J Cancer 2006;118:3030-44.

17. Bouvard V, Baan R, Straif K, et al.; WHO International Agency for Research on Cancer Monograph Working Group. A review of human carcinogens - Part B: biological agents. Lancet Oncol 2009; 10:321-2

18. Hanna TP, Kangolle AC. Cancer control in developing countries: Using health data and health services research to measure and improve access, quality and efficiency. BMC Int Health Hum Rights 2010;10:24.

19. Parkin DM. The evolution of the population-based cancer registry. Nat Rev Cancer 2006;6:603-12.

20. World Health Organization Framework Convention on Tobacco Control. 2010 global progress report on implementation of the WHO framework convention on tobacco control. Geneva (Switzerland): The Organization; 2010. Available: www.who.in /fctc/reporting/progress_report_final.pdf (accessed 2011 Nov. 20).

21. Agosti JM, Goldie SJ. Introducing HPV vaccine in developing countries - key challenges and issues. N Engl J Med 2007;356: 1908-10.

22. Machlin A, Wakefield M, Spittal M, et al. Cancer-related beliefs and behaviours in eight geographic regions. Geneva: Union for International Cancer Control; 2009.

23. Wagner AK, Graves AJ, Reiss SK, et al. Access to care and medicines, burden of health care expenditures, and risk protection: results from the World Health Survey. Health Policy 2011; $100: 151-8$

24. Barton MB, Frommer M, Shafiq J. Role of radiotherapy in cancer control in Low-Income and Middle-Income Countries. Lancet Oncol 2006;7:584-95.

25. International Atomic Energy Agency. Directory of Radiotherapy
Centers. Vienna (Austria): The Agency. Available: www-naweb .iaea.org/nahu/dirac/default.shtm (accessed 2011 Aug. 7).

26. Ferlay J, Shin HR, Bray F, et al. GLOBOCAN 2008 v.1.2, Cancer incidence and mortality worldwide: International Agency for Research on Cancer CancerBase No. 10. Lyon (France): The Agency; 2010. Available: www-dep.iarc.fr (accessed 2011 Aug. 14).

27. Knaul FM, Frenk J, Shulman LN; Global Task Force on Expanded Access to Cancer Care and Control in Developing Countries. Closing the cancer divide: a blueprint to expand access in low-and middle-income countries. Boston (MA): Harvard Global Equity Initiative; 2011.

28. World Health Organization. The world health report 2006 - working together for health. Geneva (Switzerland): The Organization; 2006.

29. Clemens MA, Pettersson G. Centre for global development working paper 95. New data on African health professionals abroad. Washington (DC): Center for Global Health; 2006. Available: www.cgdev.org/content/publications/detail/9267 (accessed 2011 June 24).

30. Shetty P. The parlous state of palliative care in the developing world. Lancet 2010;376:1453-4.

31. Union for International Cancer Control. Membership list. Geneva (Switzerland): The Union. Available: www.uicc.org /membership/list (accessed 2011 Nov. 15).

32. Union for International Cancer Control. The world cancer declaration 2008. Geneva (Switzerland): The Union. Available: www.uicc.org/declaration/download-declaration (accessed 2011 July 31)

33. World Health Organization briefing note - February 2009: access to controlled medications programme. Improving access to medications controlled under international drug conventions. Geneva (Switzerland): World Health Organization - Department of Essential Medicines and Pharmaceutical Policies, Health Systems and Services; 2009.

34. GAVI Alliance. GAVI welcomes lower prices for life-saving vaccines. Geneva (Switzerland): The Alliance; 2011. Available: www .gavialliance.org/library/news/press-releases/2011/gavi-welcomes -lower-prices-for-life-saving-vaccines/ (accessed 2011 Nov. 15).

35. Qaddoumi I, Mansour A, Musharbash A, et al. Impact of telemedicine on pediatric neuro-oncology in a developing country: the Jordanian-Canadian experience. Pediatr Blood Cancer 2007;48:39-43.

36. Hanna TP, Schreiner LJ, Dunscombe P, et al. Considerations in developing a regionalized palliative oncology program in a lowor middle-income country: a radiation oncology perspective. In: Allen BJ, Rahman MO, editors. Workshop on palliative radiotherapy for developing countries health technology and training task group. Asia-Oceania Congress of Medical Physics, Vietnam; 2008 Nov. 1. Available: www.biij.org/2008/4/e50/e50.pdf (accessed 2012 Jan. 13).

37. Vandenberg T, Nagi N, Garcia B, et al. The National Oncology Program: a Yemeni-Canadian partnership. Hematol Oncol Stem Cell ther 2009;2:294-8.

38. Elit LM, Rosen B, Jimenez W, et al. Teaching cervical cancer surgery in low- or middle-resource countries. Int J Gynecol Cancer 2010;20:1604-8

39. Story H, Love RR, Salim R, et al. Improving outcomes from breast cancer in a low income country: lessons from Bangladesh. Int J Breast Cancer; 2011 Dec. 6 [Epub ahead of print].

40. Canadian Association of Radiation Oncology International Communications Workgroup. Available: http://cicworkgroup .org/ (accessed 2011 Oct. 24) [Au:

41. Coleman MP, Forman D, Bryant H, et al. Cancer survival in Australia, Canada, Denmark, Norway, Sweden, and the UK, 1995-2007 (the International Cancer Benchmarking Partnership): an analysis of population-based cancer registry data. Lancet 2011;377:127-38.

42. Mendis S, Alwan A, editors. A prioritized research agenda for prevention and control of noncommunicable diseases. Geneva (Switzerland): World Health Organization; 2011.

Affiliations: From the Women's College Research Institute (Ginsburg), the Department of Medicine (Ginsburg, Rahim) and the Division of Global Health, Dalla Lana School of Public Health, University of Toronto, Toronto, Ont.; the International Breast Cancer Research Foundation (Ginsburg), Madison, Wis.; the Collaboration for Cancer Outcomes Research and Evaluation (Hanna), Liverpool Hospital, New South Wales, Australia; the London Regional Cancer Program (Vandenberg), London, Ont; the Division of Medical Oncology, Department of Oncology (Vandenberg), Univer- 
sity of Western Ontario, London, Ont.; the Division of Medical Oncology, Department of Oncology (Joy), University of Alberta, Edmonton, Alta.; Cross Cancer Institute (Joy, Game), Edmonton Alta.; the Division of Medical Oncology (Clemons), The Ottawa Hospital Cancer Centre; the Department of Medicine (Clemons), University of Ottawa, Ottawa, Ont.; the Department of Medicine, Division of Clinical Hematology (Game), Royal Alexandra Hospital, Edmonton, Alta.; the Departments of Medicine and Radiation Oncology (MacCormick), Cape Breton Cancer Centre, Sydney, NS Faculty of Medicine (MacCormick), Dalhousie University, Halifax, NS; the Department of Obstetrics and Gynecology (Elit), McMaster University, Hamilton, Ont.; Juravinski Cancer Centre, Hamilton Health Sciences Centre (Elit), Hamilton, Ont.; Princess Margaret Hospital (Rosen, Gospodarowicz), Toronto, Ont.; Stronach Regional Cancer Centre (Rahim), Newmarket, Ont.; the Department of Laboratory Medicine and Pathobiology (Geddie), University of Toronto, Toronto, Ont.; Canadian Partnership Against Cancer (Sutcliffe), Toronto, Ont.; Terry Fox Research Institute (Sutcliffe), Vancouver, BC; the Faculty of Graduate Studies (Sutcliffe), University of British Columbia, Vancouver, BC; the International Network of Cancer Treatment and Research Canada (Sutcliffe), Brussels, Belgium; the Department of Radiation Oncology (Gospodarowicz), University of
Toronto, Toronto, Ont.; and the Union for International Cancer Control (Gospodarowicz), Geneva, Switzerland.

Contributors: Ophira Ginsburg and Timothy Hanna contributed equally to the conception, analysis and interpretation of data, and drafting and revising the article. Theodore Vandenberg, Anil Joy, Mark Clemons, Melaku Game, Ronald MacCormick, Lorraine Elit, Barry Rosen, Yasmin Rahim, William Geddie, Simon Sutcliffe and Mary Gospodarowicz contributed substantially to conception and design and critically revised the article. All of the authors approved the final version of the of the article submitted for publication.

Acknowledgements: Ophira Ginsburg's work is supported in part by the International Breast Cancer Research Foundation, the Canadian Breast Cancer Research Alliance and the Central East Regional Cancer Program/R.S. McLaughlin Durham Regional Cancer Centre. Timothy P. Hanna's work is supported in part by a fellowship from the Ontario Institute for Cancer Research through funding provided by the Government of Ontario. Ronald MacCormick's work is supported in part by World University Services of Canada and the Royal College of Physicians and Surgeons of Canada. The work of Theodore Vandenberg and the Canadian Medical Delegation in Yemen has been supported by Nexen Yemen and the Government of Yemen. 